\title{
Effect of Rare Earth on M7C3 Eutectic Carbide in 13\% Chromium Alloy Cast Iron
}

\author{
Hoang Thi Ngoc Quyen ${ }^{\# *}$, Vu Anh Tuan ${ }^{*}$, Tran Phap Dong*, Vu Viet Quyen*, Nguyen Duong Nam* \\ ${ }^{*}$ Hanoi University of Science and Technology, Hanoi, Vietnam \\ E-mail:quyen.hoangthingoc@hust.edu.vn
}

*Vietnam Maritime University, Haiphong, Vietnam

\begin{abstract}
The crystallization process of hypoeutectic white cast iron consists of the first secreted austenite branch after the reaction of the austenite -carbide crystal is formed, and the phase crystal fills in the middle of the austenite branches. If the austenite branches are small and smooth, the crystals carbide are fine. The cast iron with $13 \%$ chromium which has $3-3.2 \%$ carbon, have the carbide crystalline as $M_{7} C_{3}$. The elements in rare earth have a strong affinity for oxygen and sulfur to produce rare earth oxides. These rare earth oxides can create heterogeneous germ center for austenite phases and smooth down these phases. The effect of rare earth on the $\mathrm{M}_{7} \mathrm{C}_{3}$ and crystals of $13 \%$ chrome white iron has been elucidated. Along with the increase of rare earth content, the microstructure of $\mathrm{M}_{7} \mathrm{C}_{3}$ with fine finely graded, more uniformly distributed, dispersed throughout the sample surface. When the carbide is fine and dispersion, will contribute to improving the properties of cast iron especially the impact strength as well as the abrasion resistance of the alloy. The research results show that in the presence of rare earth, rare earth elements created with oxygen and form La $\mathrm{O}_{3}$ and $\mathrm{Ce} 2 \mathrm{O3}$ as the nucleation for the solidification process and create the small fineness of phases. The orientation of the crystal structure of these oxides is similar to the crystal structure orientation of $\mathrm{Fe}-\gamma$ phase. Finding and proving the oxides of rare earth has crystal structure with phase $\gamma$ which will be small smooth exogenous minds that the microstructure has a smooth, small size.
\end{abstract}

Keywords — crystallization; carbide; austenite; nucleation; solidification.

\section{INTRODUCTION}

The high chromium cast iron is known as an excellent wear-resistant material and is widely used in the mining industry, cement industry, metallurgy industry. Among methods being used such as alloy [1], [2], heat treatment [3], [4] or surface treatment [5], the alloyed methods for the improvement of the mechanical properties of the material may be more appropriate. The hypereutectic white cast iron in the composition consists mainly of primary carbide so it is brittle and has low impact strength, so the research mainly focuses on the hypoeutectic white cast iron and eutectic white cast iron. Brammfit et al. [6] found that the hypoeutectic of the structure of high chromium white iron consisted of austenite branch and the eutectic of austenitecacbit. The farther away from the road along the planet, the more primary austenite and the less the microstructure of eutectic alternates between the austenite branches. Yang et al. [7] also pointed out that white cast iron with content of chromium is larger than $12 \%$ which is the type of carbide crystal changes from $\mathrm{M}_{3} \mathrm{C}$ to $\mathrm{M}_{7} \mathrm{C}_{3}$, which has the high hardness.
The hypoeutectic of cast iron has crystallization characteristics including the first branched austenitic branches, then the $\mathrm{M}_{7} \mathrm{C}_{3}$ crystalline branch, these crystals are between the branches and form the cubic of crystal. As the size of crystal's cubic is increased, the crystallization of the crystalline heat increased, coursing the carbide of particles in the boundary area, which affected the toughness and abrasion resistance of high chromium cast iron [8]. Therefore, to improve the lifespan of the hypoeutectic and eutectic white of high cast iron, people often find ways to reduce the size of the crystal, smoothing the carbide elements in the cubic of crystal. Measures to smooth the crystalline mass are to increase the number of nucleation in the same crystalline mass, increase the cooling rate in the crystallization process, adjust the chemical composition and add the heterologous germ centers (crystallization sprouts). All affect the smoothing process of the same crystal. The germ-forming elements often used for white cast iron are V [9], [10], Ti [11], RE [7], and other elements [12], [13].

The carbide of $\mathrm{M}_{7} \mathrm{C}_{3}$ crystalline has a hexagonal crystal shape, due to the very anisotropic properties of hexagonal crystals, The carbide of $\mathrm{M}_{7} \mathrm{C}_{3}$ crystalline develop mainly in the direction of 0001 , develop slowly in the direction of the 
mind forms a hexagonal crystal shaped like a rod with a length that is larger than the width, so they often reduce the toughness of the material. Morphological in white cast iron changes are a very effective way to improve the toughness and durability of white cast iron [3]. Rare earth are precious and rare elements in the earth, including 17 elements and rare elements such as scanners, ytri and lanthan and these elements are difficult to separate into separate elements. The metals contained in rare earth have a low melting point and a large atomic radius, $r_{c}=0.182 \mathrm{~nm}$, with very strong cooling during solidification.

Furthermore, elements in rare earth RE can also be used as an oxygen-reducing agent and desulphurizer of sulfur and oxygen by combining them to form RE and sulfide RE oxides shown in table 1 . Moreover, RE essentially separated from austenitic crystals during solidification. When it cools quickly, it produces polycrystalline instead of single crystals [4] and under such conditions, many austenitic branches join together and prevent them from growing together, which promotes the development of the crystal separately and smoothed structure.

The heterogeneous theory of the germinal center given by Turnbull et al, on the conditions of nucleation formation for molten metals depends mainly on two conditions. First, the substances introduced to produce the centers sprouts need to retain a solid phase on the melting point to act as a substrate for the nucleation; secondly, the mismatch between the crystal surface indexes between the two phases, the phase of the nucleation phase and the phase of the liquid metal (nucleus) must not have a big difference, also according to Bramfitt theory [7] when the non-nucleation heterogeneity $\delta$ $=6 \%$, the influence of the nucleus on the largest nucleus is also when $\delta$ has a value between 6 and 12\%, the effect of the nucleus on the nucleus at the level moderate when $\delta$ is larger than $12 \%$, is unaffected.

TABLE I

FREE ENERGY OF CHEMICAL REACTIONS BETWEEN ELEMENTS OF RARE EARTH WITH OXYGEN AND SULFUR

\begin{tabular}{|l|c|}
\hline \multicolumn{1}{|c|}{ Reactions } & $\Delta G /(\mathrm{J} / \mathrm{mol})$ \\
\hline$[\mathrm{Ce}]+2[\mathrm{O}]=\mathrm{CeO}_{2}$ & $-131000+223.10 T$ \\
\hline$[\mathrm{La}]+3 / 2[\mathrm{O}]=1 / 2 \mathrm{La}_{2} \mathrm{O}_{3}$ & $-755822+197.86 T$ \\
\hline$[\mathrm{Ce}]+3 / 2[\mathrm{O}]=1 / 2 \mathrm{Ce}_{2} \mathrm{O}_{3}$ & $-714380+185.67 T$ \\
\hline$[\mathrm{Ce}]+[\mathrm{O}]+1 / 2[\mathrm{~S}]=1 / 2 \mathrm{Ce}_{2} \mathrm{O}_{2} \mathrm{~S}$ & $-675700+164.45 T$ \\
\hline$[\mathrm{Ce}]+3 / 2[\mathrm{~S}]=1 / 2 \mathrm{Ce}_{2} \mathrm{~S}_{3}$ & $-536420+112.16 T$ \\
\hline$[\mathrm{La}]+3 / 2[\mathrm{~S}]=1 / 2 \mathrm{La}_{2} \mathrm{~S}_{3}$ & $-600509+149.95 T$ \\
\hline $\mathrm{La}]+[\mathrm{O}]+1 / 2[\mathrm{~S}]=1 / 2 \mathrm{La}_{2} \mathrm{O}_{2} \mathrm{~S}$ & $-721978+253.48 T$ \\
\hline$[\mathrm{Ce}]+[\mathrm{S}]=\mathrm{CeS}$ & $-422100+85.46 T$ \\
\hline$[\mathrm{La}]+[\mathrm{S}]=\mathrm{LaS}$ & $-445225+188.33 T$ \\
\hline
\end{tabular}

According to the evidence [14]-[17], RE oxides can be heterogeneous nucleation of $\mathrm{M} 7 \mathrm{C} 3$ carbide in high chromium cast iron. Figure 1 below provides information on the crystal geometry relationship according to the sides of $\mathrm{Ce} 2 \mathrm{O} 2 \mathrm{~S}$ and $\mathrm{M} 7 \mathrm{C} 3$. The details of the relationship are as follows:

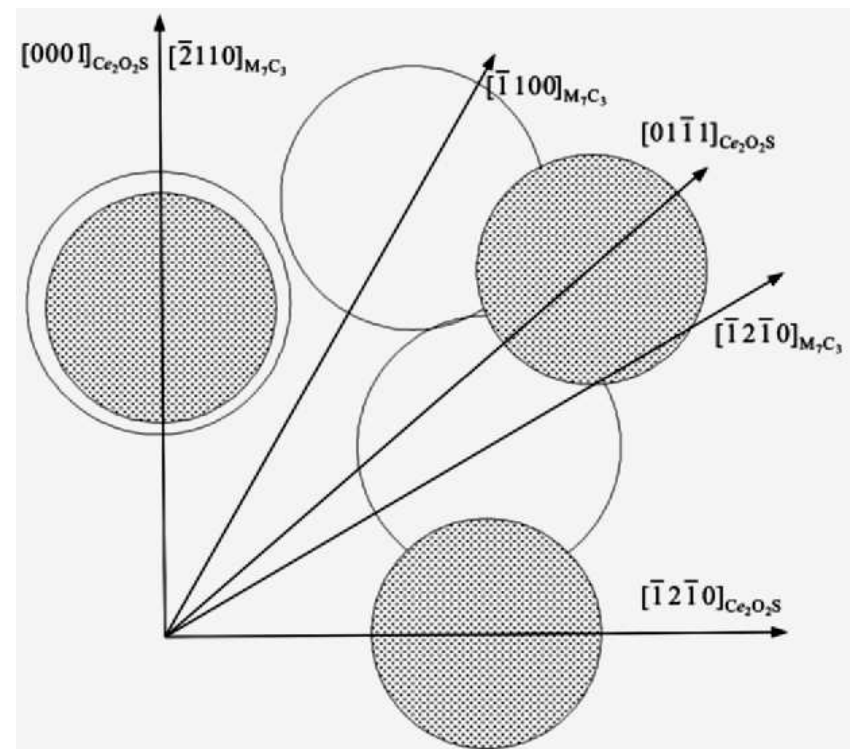

Fig 1 . The crystal geometry relationship according to the sides of $\mathrm{Ce} 2 \mathrm{O} 2 \mathrm{~S}$ and $\mathrm{M} 7 \mathrm{C} 3$

Fig. 1 depicts the crystal geometry of $\mathrm{Ce}_{2} \mathrm{O}_{2} \mathrm{~S}$ oxide and $\mathrm{M}_{7} \mathrm{C}_{3}$ carbide, the hollow circle depicting the tight hexagonal structure of $\mathrm{Ce}_{2} \mathrm{O}_{2} \mathrm{~S}$, while the dark circle describes the tightly packed hexagonal structure of $\mathrm{M}_{7} \mathrm{C}_{3}$. The crystal arrangement in the face (0001) of $\mathrm{Ce}_{2} \mathrm{O}_{2} \mathrm{~S}$ and face (2110) $\mathrm{M}_{7} \mathrm{C}_{3}$ is almost the same and this is shown in Table 2 below:

TABLE II

ALIGNMENT OF GEOMETRY BETWEEN M7C3 FASTENING SURFACES (0001) AND FASTENING SURFACE (1010) CE2O2S

\begin{tabular}{|c|c|c|c|}
\hline$[u v w]_{\mathrm{Ce} 2 \mathrm{O} 3}$ & {$[0001]$} & {$[0221]$} & {$[1210]$} \\
\hline$[u v w])_{\mathrm{\gamma}-\mathrm{Fe}}$ & {$[2110]$} & {$[1100]$} & {$[1210]$} \\
\hline$\theta$ & 0 & 19.6 & 30 \\
\hline$d_{\mathrm{Ce} 2 \mathrm{O} 3}$ & 6.833 & 10.533 & 8.016 \\
\hline$d_{\mathrm{\gamma}-\mathrm{Fe}}$ & 6.787 & 11.755 & 6.787 \\
\hline $\boldsymbol{\delta} / \%$ & 6.2 & & \\
\hline
\end{tabular}

\section{MATERIALS AND METHODS}

The high chrome white cast iron is manufactured at Thang Loi casting company, Nam Dinh. Chrome-65\% alloy is melted in medium frequency induction furnace at a temperature of $1650^{\circ} \mathrm{C}\left( \pm 50^{\circ} \mathrm{C}\right)$. The fero of rare earth is introduced into the denatured bottom of the pouring bucket to reduce the amount of burn.

Using vacuum casting method, the sample cast in sand mold $\phi 30 \mathrm{~mm} \times 300 \mathrm{~mm}$. The fero of rare earth is included in the predetermined batch; the alloy composition is shown in Table 3.

TABLE III

THE CHEMICAL OF HIGH CHROME OF WHITE CAST IRON

\begin{tabular}{|c|c|c|c|c|c|c|}
\hline Sample & $\mathbf{F e}$ & $\mathbf{C}$ & $\mathbf{M n}$ & $\mathbf{C r}$ & $\mathbf{T i}$ & $\mathbf{R E}$ \\
\hline 1 & 81.8 & 2.89 & 0.85 & 13.1 & 0.23 & 0.1 \\
\hline 2 & 80.3 & 2.76 & 0.88 & 13.3 & 0.5 & 0.3 \\
\hline 3 & 80.4 & 2.55 & 0.89 & 13.1 & 0.66 & 0.6 \\
\hline 4 & 80.2 & 2.69 & 0.87 & 13.2 & 0.6 & 0.8 \\
\hline
\end{tabular}


Table 3 records the structure of crystal deviation between the two phases (The $\mathrm{M}_{7} \mathrm{C}_{3}$ carbide and rare earth oxide $\left.\mathrm{Ce}_{2} \mathrm{O}_{2} \mathrm{~S}\right), \delta=6.2$ so it can be confirmed that rare earth oxide $\mathrm{Ce}_{2} \mathrm{O}_{2} \mathrm{~S}$ acts as a heterogeneous germ for phase $\mathrm{M}_{7} \neg \mathrm{C}_{3}$ in high chromium cast iron.

This work investigates the effect of rare earth elements on the size of the same crystal between the carbide $\mathrm{M}_{7} \mathrm{C}_{3}+\gamma$ and on the morphology of the $\mathrm{M}_{7} \mathrm{C}_{3}$ crystal and the $13 \%$ chromium cast iron system with carbon content of about 3$3 . \%$. The microstructure of crystalline of high chrome white cast iron was observed on optical microscopes (x500, bituminous corrosive color impregnation and scanning electron microscopy (x1500, secondary electron image).

\section{RESULTS AND DISCUSSIONS}

\section{A. Crystallization with Crystals of $13 \%$ High Chrome White Cast Iron}

After casting: the diagram of X-ray diffraction (Fig. 2) indicates the presence of the austenitic phase and the carbite of $\mathrm{M}_{7} \mathrm{C}_{3}$ in the microstructure. The cast iron with $13 \%$ chromium is pre-cast iron which has crystalline characteristics consisting of primary austenitic branches that secrete and fill in between the austenitic branches. By SEM (Fig. 3) and distribution of $\mathrm{M}_{7} \mathrm{C}_{3}$ carbide of eutectic (Fig. 4), it can be seen that the crystallization between $\mathrm{M}_{7} \mathrm{C}_{3}$ and austenite which indicated the crystallization of the white cast iron with $13 \% \mathrm{Cr}$. The austenite phase is formed naturally, dispersed austenite particles.

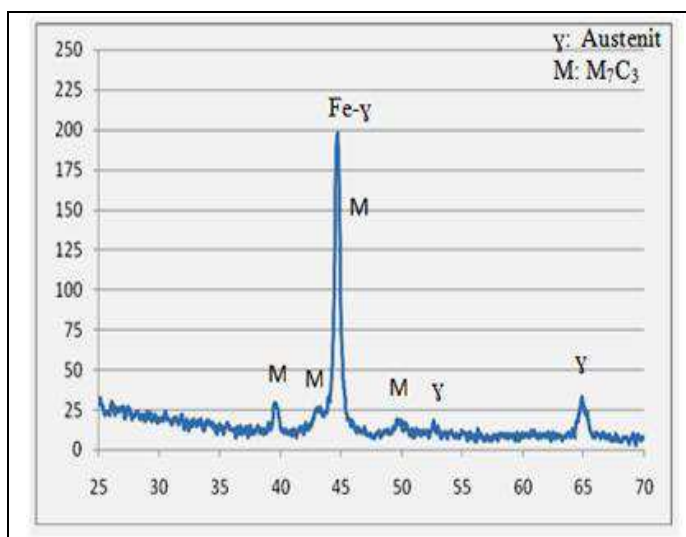

Fig 2. XRD of sample 1 after casting

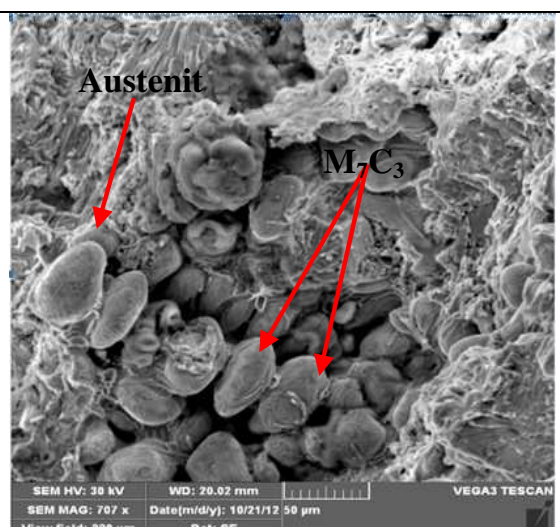

Fig 3. SEM of austenite primary and M7C3 eutectic

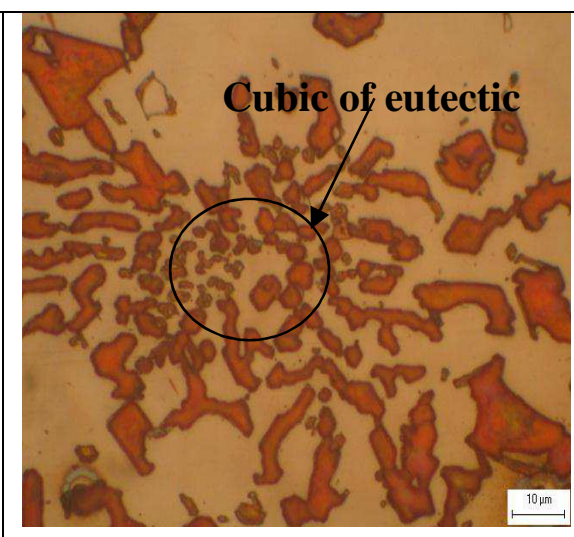

Fig 4. The distribution of M7C3 carbide of eutectic
The crystallization between austenite and the carbide will formed and the between the branches. If the crystallization of the primary austenite phase is smooth and continuous, the crystallization phase becomes fine and discrete. Figure 3 shows the distribution of the $\mathrm{M}_{7} \mathrm{C}_{3}$ carbide of a crystallization area, in the center of crystallization area, it has the finer-grained, the farther away the center of its, the grain size is increased. Thus the distribution of the carbide is related to the size of the crystallization. The crystallization cubic size is related to the crystallization of the primary austenite. If the primary austenite is small, the crystallization size is fine, and all the carbide distributed in the crystallization area are fine.

\section{B. The Heterogeneous Nucleation Process for the Austenitic Phase of Rare Earth for the 13\% Chromium Cast Iron}

Expand enrolment in colleges, vocational schools, in remote areas; building inter-school regimes for seafarers after going to sea for 1 to 2 years to attract students; strengthen the dissemination of training models according to the pilot project on maritime officers training approved by the Ministry of Transport. Expand training facilities to be located in coastal areas, convenient for young people in coastal areas, and take advantage of the river environment to combine vocational training and the quality of seafarers. Rare earth are rare elements in the earth including 17 elements: scan, ytri, lanthanium ... These elements are difficult to separate. Metals found in rare earths have a low melting point, a large atomic radius $r_{c}=0.182 \mathrm{~nm}$, and a very large degree of cooling during freezing [3].

EDS spectra of the austenitic branches of samples No.1 and 4 (Fig. 5) in the presence of rare earth elements such as $\mathrm{La}, \mathrm{Ce}$ and Oxi in this composition showed that the elements present in the cast iron Chromium is studied in the form of rare earth oxides $\left(\mathrm{CeO}_{2}, \mathrm{La}_{2} \mathrm{O}_{3}, \mathrm{Ce}_{2} \mathrm{O}_{3}\right.$..). The cause of this oxide formation is that the rare earth elements have a strong affinity for the oxide element [18]. Zhou et al. [19] argue that there are two conditions for nucleation: first, the inoculants that produce the nucleus require a high melting point to activate act as a germicide, the second one. The difference between the crystal indexes between the two phases: the germination phase and the crystalline phase on the germination center must not be large.

Bramfitt [6] theory suggests that when the difference in crystallinity index $(\delta)$ between germination-phase crystalline phase on germination: with $\delta=6 \%$, the suitability of the germination center is greatest, when $\delta$ Values range from 6 to $12 \%$, moderately, and when $\delta>12 \%$ are ineffective, i.e., they cannot become nucleated. The difference in crystal lattice of $\mathrm{Ce}_{2} \mathrm{O}_{3}$ and Austenite in the direction of [1210] $\mathrm{Ce}_{2} \mathrm{O}_{3} / /$ [010] $\mathrm{\gamma}-\mathrm{Fe}$ is 7.7 [20]. This means that $\mathrm{Ce}_{2} \mathrm{O}_{3}$ may cause heterogeneous nucleation for the primary austenite phase. The austenite has finer grain. 


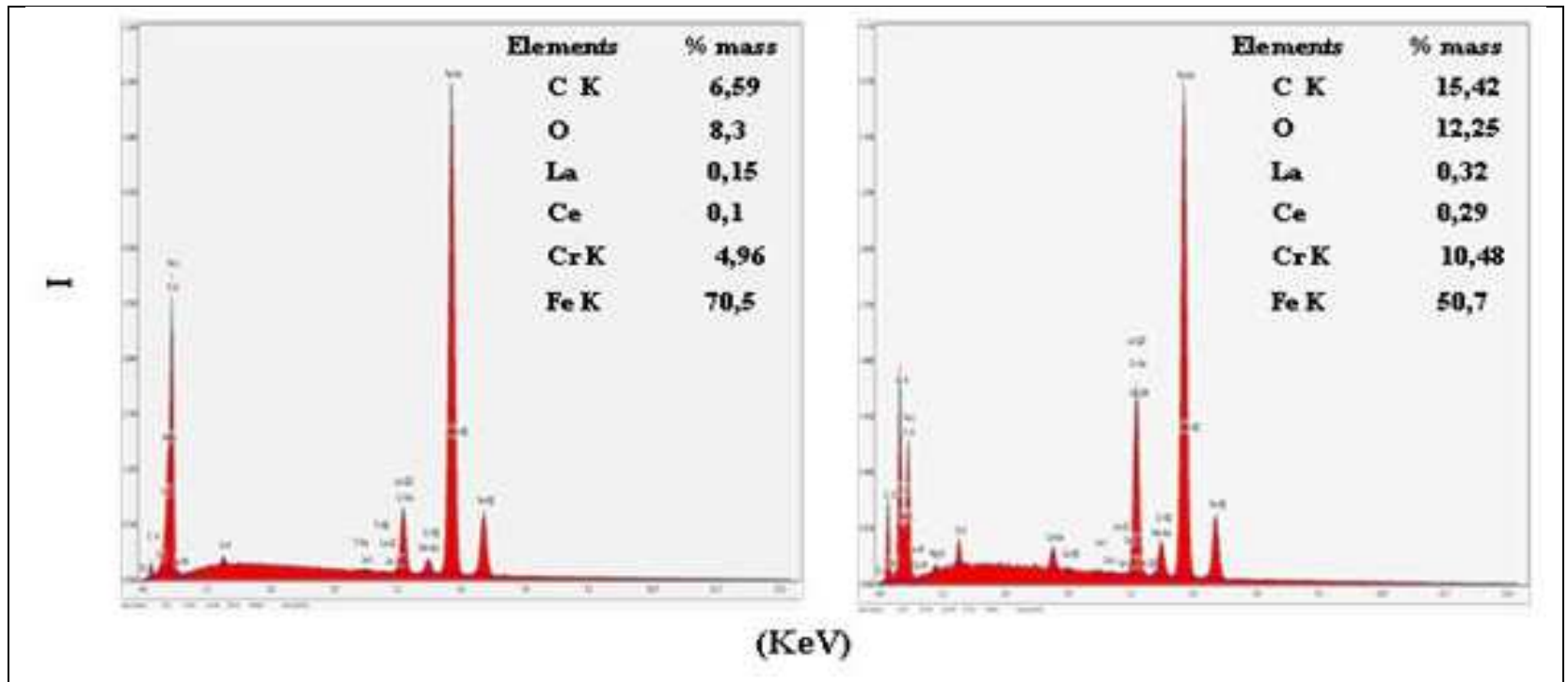

Fig 5. EDS of primary branches with No. 1 and No.4

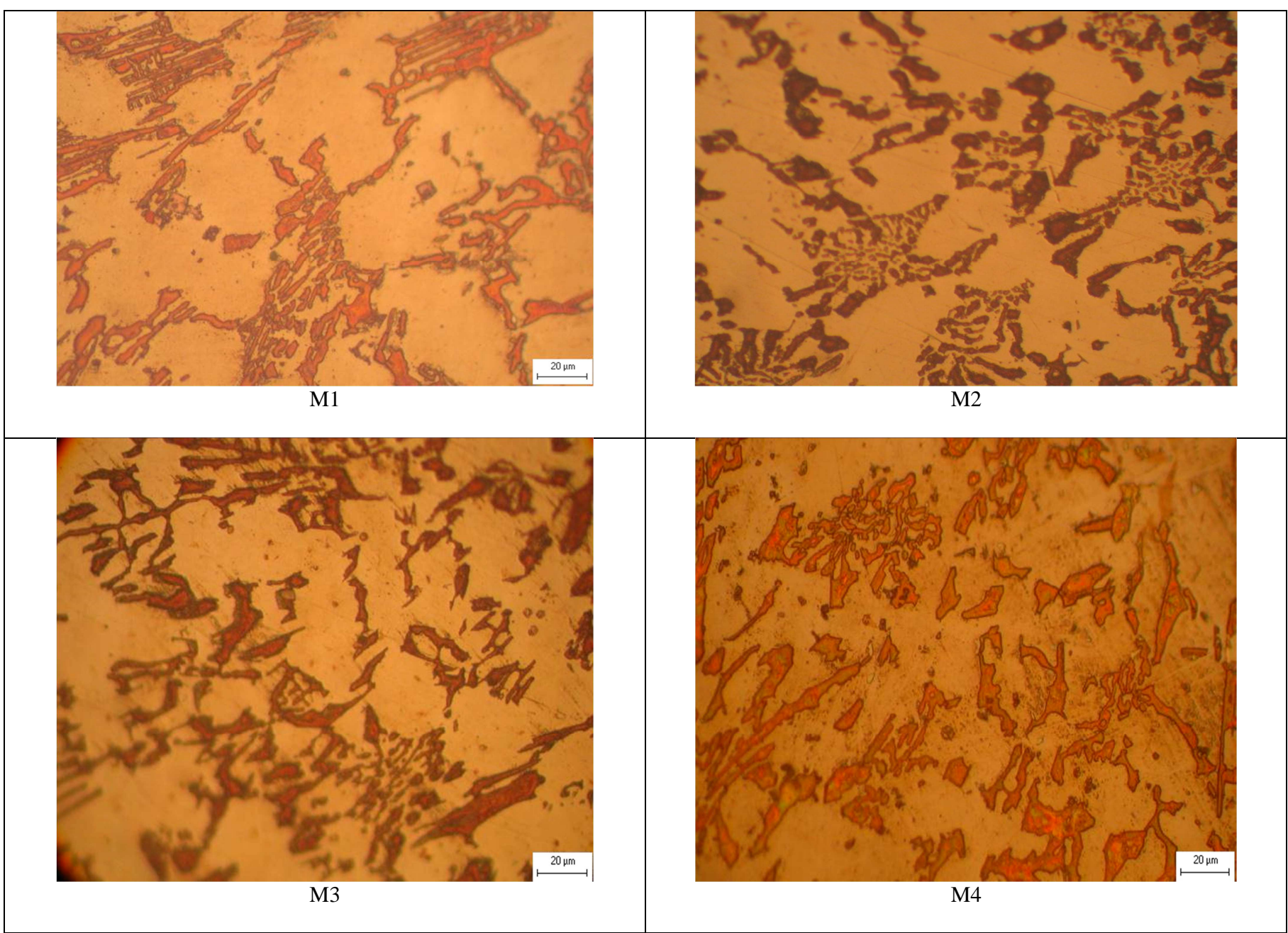

Fig 6. Optical microscopy images capture the surface of the samples in the direction of the rare earth

\section{The Influence of the RE Elements on the Chromium Content of the Chromium Oxide}

Fig. 6 is an optical microscope that the microstructure of the alloys according to the increasing of the rare earth content (chemical composition shown in Table 1). According to the increase of rare earth content, the microstructure of alloys in different alloys. From the original microstructure (Alloy 1 ) with $0.1 \%$ RE in the composition, the carbide of crystalline is the raw carbide, the diameter of the same large area, the concentration of high carbide, when the rare earth with content of $0.3 \% \mathrm{RE}$, the same microstructure has changed the concentration level of the 
same coin has lower continuity is also smaller. As the amount of rare earth increased to $0.8 \%$, the diameter of the same area became relatively small, the carbide has a uniform dispersion and finer grain, on the surface appear more and more small carbide are scattered. As analyzed by the introduction of rare earth into liquid pigs, they purify oxygen and sulfur in molten cast iron to produce rare earth oxides such as $\mathrm{CeO}_{2}, \mathrm{La}_{2} \mathrm{O}_{3}$, and $\mathrm{Ce} 2 \mathrm{O} 3$. The $\mathrm{Ce}_{2} \mathrm{O}_{3}$ may cause heterogeneous nucleation of the austenitic phase and a smooth austenite phase.

On the other hand, the presence of RE at the solid/liquid phase boundary of the first stage of crystallization will promote the smoothening of branch austenite, reducing the gaps within the branches where the same crystal reactions occur. Also when crystallized, the compound of RE decays before the austenite crystal. When cooled sufficiently quickly they produce polycrystalline rather than monocrystalline [5] and under such conditions several austenite branches are bonded together, whereby the same fines are enclosed by small branched austenite branches In such a way, the growth of the same crystal is limited by the austenite shell, which results in the formation of identical crystals and promotes the development of the same crystal and smoothens the crystal structure [21]. Changing the morphology of the white pig iron is a very effective way to improve the toughness and durability of the white cast iron. By introducing rare earth into a finer, smoother, uniform distribution across the surface of the sample, it is desirable to improve the wear and tear of the alloy.

\section{CONCLUSIONS}

The white cast iron $13 \%$ chromium with content of $-3.2 \%$ carbon is pre-cast iron with the crystalline characteristics of the austenitic branches first and then the same austenite - the new $\mathrm{M}_{7} \mathrm{C}_{3}$ carbide secreted and filled between branches. Smoothing austenite primary means smoothing the crystallization. Rare earth oxides in $13 \%$ chromium cast oxides such as $\mathrm{La}_{2} \mathrm{O}_{3}, \mathrm{Ce}_{2} \mathrm{O}_{3}$, and these oxides act as nucleating agents for the austenitic phases and make these finer austenitic phases. According to the increase of rare earth content, the size of the crystallization has been reduced and thus the microstructure of the crystallization $\mathrm{M}_{7} \mathrm{C}_{3}$ carbide is gradually smaller and the same cores are more uniformly distributed.

\section{REFERENCES}

[1] X. D. Pham, A. T. Hoang, and D. N. Nguyen, "A Study on the Effect of the Change of Tempering Temperature on the Microstructure Transformation of $\mathrm{Cu}-\mathrm{Ni}-\mathrm{Sn}$ Alloy," Int. J. Mech. Mechatronics Eng., vol. 18, no. 04, pp. 27-34, 2018.

[2] X. D. Pham, A. T. Hoang, D. N. Nguyen, and V. V Le, "Effect of Factors on the Hydrogen Composition in the Carburizing Process," Int. J. Appl. Eng. Res., vol. 12, no. 19, pp. 8238-8244, 2017.
[3] A. T. Hoang, V. V. Le, D. N. Nguyen, and A. X. Nguyen, "A study of the changes in microstructure and mechanical properties of multipass welding between 316 stainless steel and low carbon steel," $J$. Adv. Manuf. Technol., vol. 12, no. 2, pp. 23-35, 2018.

[4] T. N. Le, M. K. Pham, A. T. Hoang, and D. N. Nguyen, "Microstructures and elements distribution in the transition zone of carbon steel and stainless steel welds," J. Mech. Eng. Res. Dev., vol. 41, no. 3, pp. 27-31, 2018.

[5] D. N. N. Anh Tuan Hoang, Thi Thanh Van Tran, Van Bach Nguyen, "Effect of heat treatment process on the microstructure and mechanical properties of the spray coating Ni-Cr on CT38 steel," Int. J. Adv. Sci. Eng. Inf. Technol., vol. 9, no. 2, 2019.

[6] B. L. Bramfitt, "Planar lattice disregistry theory and its application on heterogistry nuclei of metal," Met. Trans, vol. 1, no. 7, pp. 19871995, 1970.

[7] Y. Jian et al., "Effect of RE oxide on growth dynamics of primary austenite grain in hardfacing layer of medium-high carbon steel," $J$. Rare Earths, vol. 30, no. 8, pp. 814-819, 2012.

[8] S. G. Liu et al., "Application of quenching-partitioning-tempering process and modification to a newly designed ultrahigh carbon steel," Mater. Des. vol. 56, pp. 37-43, 2014.

[9] M. Filipovic and E. Romhanji, "Strain hardening of austenite in FeCr-C-V alloys under the repeated impact," Wear, vol. 270, no. 1112, pp. 800-805, 2011.

[10] M. K. Pham, D. N. Nguyen, and A. T. Hoang, "Influence of Vanadium Content on the Microstructure and Mechanical Properties of High-Manganese Steel," Int. J. Mech. Mechatronics Eng., vol. 18, no. 2, pp. 141-147, 2018.

[11] A. Bedolla-Jacuinde, S. L. Aguilar, and B. Hernandez, "Eutectic modification in a low-chromium white cast iron by a mixture of titanium, rare earth, and bismuth: I. Effect on microstructure," $J$. Mater. Eng. Perform. vol. 14, no. 2, pp. 149-157, 2005.

[12] J. Wang et al., "Influence of secondary carbides precipitation and transformation on hardening behavior of a $15 \mathrm{Cr}-1 \mathrm{Mo}-1.5 \mathrm{~V}$ white iron," Mater. Charact., vol. 55, no. 3, pp. 234-240, 2005.

[13] P. P. Hellstén, J. M. Salminen, K. S. Jørgensen, and T. H. Nystén, "Use of potassium formate in road winter deicing can reduce groundwater deterioration," Environ. Sci. Technol., vol. 39, no. 13, pp. 5095-5100, 2005.

[14] X. Wu, J. Xing, H. Fu, and X. Zhi, "Effect of titanium on the morphology of primary M7C3 carbides in hypereutectic high chromium white iron," Mater. Sci. Eng. A, vol. 457, no. 1-2, pp. 180-185, 2007.

[15] A. Bedolla-Jacuinde, R. Correa, J. G. Quezada, and C. Maldonado, "Effect of titanium on the as-cast microstructure of a $16 \%$ chromium white iron," Mater. Sci. Eng. A, vol. 398, no. 1-2, pp. 297-308, 2005.

[16] A. Bedolla-Jacuinde, B. Hernández, and L. Béjar-Gómez, "SEM study on the M7C3 carbide nucleation during eutectic solidification of high-chromium white irons," Zeitschrift für Met., vol. 96, no. 12, pp. $1380-1385,2005$.

[17] M. Filipovic, Z. Kamberovic, and M. Korac, "Solidification of high chromium white cast iron alloyed with vanadium," Mater. Trans., vol. 52, no. 3, pp. 386-390, 2011.

[18] X. H. Tang, R. Chung, D. Y. Li, B. Hinckley, and K. Dolman, "Variations in microstructure of high chromium cast irons and resultant changes in resistance to wear, corrosion and corrosive wear," Wear, vol. 267, no. 1-4, pp. 116-121, 2009.

[19] Z. Jiyang, "Colour metallography of cast iron," China foundry, vol. 6, no. 1, pp. 57-69, 2009.

[20] A. B. Jacuinde and W. M. Rainforth, "The wear behaviour of highchromium white cast irons as a function of silicon and Mischmetal content," Wear, vol. 250, no. 1-12, pp. 449-461, 2001.

[21] Y. Matsubara, K. Ogi, and K. Matsuda, "Eutectic Solidification of High-Chromium Cast Iron--Eutectic Structures and Their Quantitative Analysis," Am. Foundrymen's Soc. Trans., vol. 89, pp. 183-196, 1981. 